\title{
Epidural anesthesia combined with sedation with dexmedetomidine for appendectomy in a patient with amyotrophic lateral sclerosis: a case report
}

\author{
Mikako Kusakai, Atsushi Sawada*, Natsumi Kii, Yasuyuki Tokinaga, Naoyuki Hirata and Michiaki Yamakage
}

\begin{abstract}
Background: Patients with amyotrophic lateral sclerosis (ALS) present increased risks for anesthesia-related complications. We present a case of epidural anesthesia combined with sedation with dexmedetomidine for open appendectomy in a patient with ALS who refused invasive mechanical ventilation.

Case presentation: A 50-year-old man with a 3-year history of ALS was scheduled to undergo open appendectomy due to repeated appendicitis. He refused to undergo invasive mechanical ventilation using an endotracheal tube. Hence, we decided to administer epidural anesthesia combined with sedation with dexmedetomidine for anesthesia during the surgical procedure. The patient underwent open appendectomy without complications and with no pain or discomfort during surgery. There were no neurological complications at the 3-month follow-up after surgery.

Conclusions: Epidural anesthesia combined with sedation with dexmedetomidine may be effective for the anesthetic management of patients who would benefit from regional anesthesia.
\end{abstract}

Keywords: Amyotrophic lateral sclerosis, Epidural anesthesia, Dexmedetomidine

\section{Background}

Amyotrophic lateral sclerosis (ALS) is a progressive neurodegenerative disease that affects both upper and lower motor neurons and finally leads to death due to respiratory insufficiency [1]. Patients with ALS present increased risks for anesthesia-related complications and require careful perioperative management. General anesthesia may cause fatal respiratory depression because ALS patients are known to be sensitive to neuromuscular blocking agents. Although regional anesthesia is considered to be relatively contraindicated in patients with central nervous system (CNS) disorders, regional anesthesia reportedly did not lead to postoperative worsening of neurologic deficits as compared to preoperative findings in 136 patients with CNS disorders [2]. Here, we report a case of epidural anesthesia combined with sedation with dexmedetomidine for open appendectomy

\footnotetext{
* Correspondence: atusihon7@gmail.com

Department of Anesthesiology, Sapporo Medical University School of Medicine, South 1, West 16, Chuo-ku, Sapporo, Japan
}

in an ALS patient who refused to undergo invasive mechanical ventilation.

This case is significant for the indication for regional anesthesia and the perioperative anesthetic management, which enabled avoidance of respiratory insufficiency and was not associated with worsening of neurological symptoms at a 3-month postoperative follow-up in our patient with ALS.

\section{Case presentation}

Approval and consent for publication of this report were obtained from the patient and his wife.

A 50-year-old man (body weight $55 \mathrm{~kg}$; height $168 \mathrm{~cm}$ ) with a 3-year history of ALS was scheduled to undergo open appendectomy due to repeated appendicitis. Clinically, he had advanced bulbar symptoms with dysarthria and dysphagia and muscle weakness in both upper limbs. He had no muscle weakness in his lower limbs. His kidney function was normal. Pulmonary function testing indicated that his forced vital capacity (FVC) was 
3.15 L and \%FVC was $85.6 \%$. Although he accepted future placement of a percutaneous endoscopic gastrostomy for nutritional supplementation and the necessary equipment for non-invasive mechanical ventilation for pulmonary support, he refused to undergo future invasive mechanical ventilation using an endotracheal tube or tracheotomy in the advanced stages of ALS. In order to avoid the respiratory depression associated with general anesthesia, we decided to administer epidural anesthesia combined with sedation with dexmedetomidine for anesthesia during the surgical procedure.

After obtaining the patient's informed consent, we transferred him to the operating room and established standard monitoring. After placing the patient in the right lateral position, an 18-gauge Tuohy needle and loss-of-resistance technique with saline were used to obtain epidural access at the T12/L1 vertebral interspace. After careful aspiration to avoid intravascular and intrathecal injection, $11 \mathrm{~mL}$ of $1.5 \%$ lidocaine with $1: 200,000$ epinephrine was injected directly via the Tuohy needle. Then, an epidural catheter was placed for intraoperative and postoperative analgesia. We confirmed anesthesia of the T6 to L3 dermatomes using the cold test with ice. Active hip, knee, and ankle flexion were maintained during the surgery. Dexmedetomidine infusion was administered for sedation at $4 \mu \mathrm{g} / \mathrm{kg} / \mathrm{h}$ for $10 \mathrm{~min}$ and continued at $0.4 \mu \mathrm{g} / \mathrm{kg} / \mathrm{h}$ along with $3 \mathrm{~L} / \mathrm{min} \mathrm{O}_{2}$ via a face mask. The patient underwent open appendectomy without complications. The operative time was $43 \mathrm{~min}$. He had no pain or discomfort intraoperatively. Dexmedetomidine infusion was terminated at the end of surgery. For postoperative analgesia, $0.125 \%$ levobupivacaine was continuously infused at $4 \mathrm{~mL} / \mathrm{h}$ via the epidural catheter. He was monitored overnight in the intensive care unit (ICU) to assess his respiratory status and was shifted from the ICU the day after surgery. The patient walked without support after discharge from the ICU. There was no worsening of motor function in his lower limbs or interference with passing urine both during the effect of epidural analgesia and after it had worn off. The epidural catheter was removed on the fourth day after surgery, and the patient was discharged home on the fifth day after surgery. There were no neurological complications due to epidural anesthesia at the 3-month follow-up after surgery.

\section{Conclusions}

ALS is a fatal neurodegenerative disease characterized by death of upper and lower motor neurons. Respiratory muscle weakness occurs due to loss of bulbar, cervical, and thoracic motor neurons [3]. Due to the inherent muscle weakness, general anesthesia combined with muscle relaxants may cause fatal respiratory insufficiency in patients with ALS. Historically, regional anesthesia has been relatively contraindicated in patients with CNS disorders for fear of causing postoperative worsening of neurological symptoms [4]. On the other hand, a previous prospective investigation reported no new or worsening of postoperative neurologic deficits as compared to preoperative findings in 139 patients with preexisting CNS disorders who underwent regional anesthesia [2]. The reduction of FVC has been previously reported to be negligible under lumbar epidural anesthesia in patients without respiratory depression [5]. Although lumbar and low thoracic epidural anesthesia was previously reported to induce a temporary reduction in FVC in a patient with ALS, it was not associated with the development of hypoxia or any clinical symptoms [6]. In our case, the patient had no respiratory depression after epidural anesthesia. In the event that epidural anesthesia severely depressed respiratory function in our patient, we intended to noninvasively support respiration via a ventilation mask until the respiratory depression induced by epidural anesthesia subsided. Therefore, we administered lidocaine as the local anesthetic for epidural anesthesia despite its greater potential to cause motor blockade as compared to other local anesthetic agents, because lidocaine has a shorter duration of action than levobupivacaine and ropivacaine.

Dexmedetomidine is a highly selective $\alpha_{2}$-adrenoceptor agonist. Its clinical effects include sedation, analgesia, and prevention of a detrimental stress response without respiratory depression [7]. Previous randomized trials revealed that dexmedetomidine provided safe and adequate sedation in patients with the risk of pulmonary aspiration who underwent upper endoscopy [8] or endoscopic interventions [9]. Dexmedetomidine provided appropriate sedation and comfort to our patient with ALS without respiratory depression or pulmonary aspiration.

In summary, epidural anesthesia combined with sedation with dexmedetomidine may be effective and suitable for the anesthetic management of certain patients with ALS.

\section{Abbreviations \\ ALS: Amyotrophic lateral sclerosis; CNS: Central nervous system; FVC: Forced vital capacity; ICU: Intensive care unit}

\section{Acknowledgements}

The authors thank Masayuki Ishii, M.D., Ph.D. Department of Surgery, Surgical Oncology and Science, Sapporo Medical University School of Medicine, Sapporo, Japan, for assistance in the perioperative management.

Funding

The authors have no sources of funding to declare related to this manuscript.

\section{Availability of data and materials}

The datasets are available from the corresponding author on reasonable request.

Authors' contributions

MK helped with the administration of anesthesia to the patient. AS conducted the perioperative management, administered the anesthesia, and wrote the manuscript. NK helped with the writing of the manuscript. $\mathrm{YT}, \mathrm{NH}$, and MY 
helped with the perioperative management of the patient. All authors read and approved the final manuscript.

Ethics approval and consent to participate

Ethics approval is not applicable because this manuscript is a case report.

\section{Consent for publication}

Written informed consent was obtained from the patient for the publication of this case.

\section{Competing interests}

The authors declare that they have no competing interests.

\section{Publisher's Note}

Springer Nature remains neutral with regard to jurisdictional claims in published maps and institutional affiliations.

Received: 12 November 2018 Accepted: 17 December 2018

Published online: 26 December 2018

\section{References}

1. Prabhakar A, Owen CP, Kaye AD. Anesthetic management of the patient with amyotrophic lateral sclerosis. J Anesth. 2013;27:909-18.

2. Hebl JR, Horlocker TT, Schroeder DR. Neuraxial anesthesia and analgesia in patients with preexisting central nervous system disorders. Anesth Analg. 2006:103:223-8.

3. Hardiman $\mathrm{O}$. Symptomatic treatment of respiratory and nutritional failure in amyotrophic lateral sclerosis. J Neurol. 2000;247:245-51.

4. Horlocker TT, Wedel DJ. Neurologic complications of spinal and epidural anesthesia. Reg Anesth Pain Med. 2000;25:83-98.

5. Freund FG, Bonica JJ, Ward RJ, Akamatsu TJ, Kennedy WF Jr. Ventilatory reserve and level of motor block during high spinal and epidural anesthesia. Anesthesiology. 1967:28:834-7.

6. Hara K, Sakura S, Saito Y, Maeda M, Kosaka Y. Epidural anesthesia and pulmonary function in a patient with amyotrophic lateral sclerosis. Anesth Analg. 1996;83:878-9.

7. Hall JE, Uhrich TD, Barney JA, Arain SR, Ebert TJ. Sedative, amnestic, and analgesic properties of small-dose dexmedetomidine infusions. Anesth Analg. 2000;90:699-705.

8. Demiraran Y, Korkut E, Tamer A, Yorulmaz I, Kocamen B, Sezen G, Akcan Y. The comparison of dexmedetomidine and midazolam used for sedation of patients during upper endoscopy: a prospective, randomized study. Can J Gastroenterol. 2007;21:25-9.

9. Takimoto K, Ueda T, Shimamoto F, Kojima Y, Fujinaga Y, Kashiwa A, Yamauchi H, Matsuyama K, Toyonaga T, Yoshikawa T. Sedation with dexmedetomidine hydrochloride during endoscopic submucosal dissection of gastric cancer. Dig Endosc. 2011;23:176-81.

\section{Submit your manuscript to a SpringerOpen ${ }^{\circ}$ journal and benefit from:}

- Convenient online submission

- Rigorous peer review

- Open access: articles freely available online

- High visibility within the field

- Retaining the copyright to your article

Submit your next manuscript at $\boldsymbol{\nabla}$ springeropen.com 